\title{
Using clinical risk factors and bone mineral density to determine who among patients undergoing bone densitometry should have vertebral fracture assessment
}

\author{
T. J. Vokes • D. L. Gillen
}

Received: 12 October 2009/Accepted: 13 January 2010 / Published online: 20 March 2010

(C) The Author(s) 2010. This article is published with open access at Springerlink.com

\begin{abstract}
Summary Vertebral fracture assessment (VFA) is a new method for imaging thoracolumbar spine on bone densitometer. Among patients referred for bone densitometry, the selection of patients for VFA testing can be optimized using an index derived from clinical risk factors and bone density measurement.

Purpose VFA, a method for imaging thoracolumbar spine on bone densitometer, was developed because vertebral fractures, although common and predictive of future fractures, are often not clinically diagnosed. The study objective was to develop a strategy for selecting patients for VFA.

Methods A convenience sample from a university hospital bone densitometry center included 892 subjects (795 women) referred for bone mineral density (BMD) testing. We used questionnaires to capture clinical risk factors and dual-energy X-ray absorptiometry to obtain BMD and VFA.
\end{abstract}

Presented in an abstract form at the 2005 Annual Meeting of American Society of Bone and Mineral Research

Supported by grant K23 AR048205-01A1 from the National Institute of Health and by Fred and Susan Novy Foundation

\section{T. J. Vokes}

Department of Medicine, University of Chicago,

Chicago, IL, USA

D. L. Gillen

Department of Statistics, University of California,

Irvine, CA, USA

\section{T. J. Vokes $(\varangle)$}

Section of Endocrinology, University of Chicago,

5841 S. Maryland, MC1027,

Chicago, IL 60637, USA

e-mail: tvokes@uchicago.edu
Results Prevalence of vertebral fractures was $18 \%$ in women and $31 \%$ in men ( $p=0.003$ for gender difference). In women, age, height loss, glucocorticoid use, history of vertebral and other fractures, and BMD T-score were significantly and independently associated with vertebral fractures. A multivariate model which included above predictors had an area under the receiver operating curve of 0.85 with $95 \%$ confidence interval (CI) of 0.81 to 0.89 . A risk factor index was derived from the above multivariate model. Using a level of 2 as a cut-off yielded 93\% sensitivity $(95 \%$ CI 87,96$)$ and $48 \%$ specificity $(95 \%$ CI 69,83 ). Assuming a $15 \%$ prevalence of vertebral fractures, this cut-off value had a $24 \%$ positive and $97 \%$ negative predictive value and required VFA scanning of three women at a cost of $\$ 60$ (assuming a $\$ 20$ cost/VFA scan) to detect one with vertebral fracture(s).

Conclusions Selecting patients for VFA can be optimized using an index derived from BMD measurement and easily obtained clinical risk factors.

Keywords Bone densitometry · FRAX - Osteoporosis . Vertebral fractures · VFA

\section{Introduction}

Vertebral fractures are the most common osteoporotic fractures. They are important to detect because they are associated with significant morbidity, mortality, and reduced quality of life [1-3], and because they strongly predict future fractures [4-7]. Furthermore, the increase in fracture risk associated with vertebral fractures is independent of, and additive to, bone mineral density (BMD) measurement [7-9]. Therefore, having information about vertebral fractures in conjunction with BMD allows 
clinicians to better assess fracture risk and select appropriate therapies. Because only one third of vertebral fractures found on radiographs are clinically diagnosed [10-12], imaging is necessary for their detection. This has required radiographs which are usually not obtained in the course of clinical evaluation of osteoporosis. Further, even when vertebral fractures are present on radiographs, they are often not recognized by the reporting radiologist and do not lead to the diagnosis and appropriate treatment of osteoporosis $[12,13]$. Recognition of the importance of vertebral fractures for osteoporosis care, coupled with the realization that they are often not clinically apparent, has led to the development of vertebral fracture assessment (VFA). VFA is a method for imaging the thoracolumbar spine on bone densitometers, usually obtained at the time of BMD measurement. This rapid and simple procedure is associated with low cost and radiation exposure, and has a reasonably good ability to detect vertebral fractures (reviewed in [14]).

However, it is not clear how to best select patients for VFA imaging, maximizing the detection of vertebral fractures yet minimizing scanning of subjects in whom finding a fracture is unlikely. The International Society for Clinical Densitometry (ISCD) has formulated recommendations for selecting patients for VFA [14], though such recommendations have not been tested in practice. Therefore, we set out to determine which patients among those who present for BMD measurement should have VFA imaging. We postulated that the information needed for decision making should be easily obtained through a short interview or intake questionnaire to permit its eventual use in a busy densitometry practice. We included risk factors such as age, history of fractures, and height loss, which were found in population studies to best identify subjects with vertebral fractures on radiographs $[15,16]$. We also added the results of BMD measurement, since it is readily available at the time of VFA testing, and the history of glucocorticoid use, which is associated with increased risk of vertebral fractures [17-19] and is a common indication for BMD testing.

\section{Methods}

Study subjects The study was approved by the University of Chicago's Institutional Review Board and all participants signed a written informed consent. A convenience sample included 974 subjects ( 869 women) recruited when they presented for BMD measurement as part of their clinical care between 2001 and 2007. The densitometry facility performs all BMD testing at the University of Chicago, and patients are referred mostly by University of Chicago faculty. The patients come from the geographic area around the campus to receive their primary care at the University of Chicago or from the Metropolitan Chicago Area and Northwest Indiana for tertiary care. It is not known which of the study subjects, or densitometry patients in general, belong to which of these groups, as they cannot be strictly defined by geography. There were no specific criteria for including patients in the study - it required that the study personnel be present and that the subjects consent to participate.

Procedures The subjects completed a questionnaire which included information on personal and family history of fractures and their circumstances, young adult height and weight, medical history, medication use, and personal habits such as smoking, alcohol consumption, calcium intake, and activity level. Height and weight were measured using standard clinic equipment. Using this information, we also calculated the 10 -year probability of major osteoporotic fractures using the version 3 of FRAX ${ }^{\circledR}$ web-based tool [20].

VFA images and BMD measurements of the lumbar spine and proximal femur were obtained by two ISCDcertified technologists using a Prodigy densitometer (GE Medical Systems, Madison, WI, USA). All VFA images were evaluated by one ISCD-trained clinician (TJV) using Genant semi-quantitative approach [21] as recommended by the ISCD $[14,22]$ where vertebra with a fracture on visual inspections is assigned the following grades: grade 1 (mild) fracture represents a reduction in vertebral height of $20-25 \%$; grade 2 (moderate) a reduction of $26-40 \%$; and grade 3 (severe) a reduction of over $40 \%$. A subject in the vertebral fracture group had at least one grade 2 fracture or two grade 1 fractures. The main analysis was performed after excluding subjects with a single grade 1 fracture $(N=$ 31) because it is often not clear whether these represent true fractures or non-fracture deformities, because grade 1 fractures are not as clearly predictive of future fractures as are higher grades [23], and because they are often difficult to conclusively diagnose on VFA [14, 22, 24].

Definition of risk factors used in analysis Height loss was calculated by subtracting the measured height from the selfreported young adult height. Self-reported vertebral fractures were present if the subject reported spine or vertebral fractures (excluding neck or cervical fractures) in response to the question "have you had any broken bones". Nonvertebral (peripheral) fracture was defined as any fracture occurring after age 25 , in the course of usual physical activity, excluding fractures of the face, fingers, and toes, or those resulting from a motor vehicle accident. Glucocorti- 
coid use (systemic but not inhaled) was defined as at least $5 \mathrm{mg} /$ day of prednisone or equivalent for at least 3 months (cumulative exposure equivalent to at least $0.450 \mathrm{~g}$ of prednisone), as recommended by the American College of Rheumatology [25]. For BMD measurement, the lower of the lumbar spine or proximal femur T-score (femoral neck or total hip) was used for analysis as recommended by the ISCD [26].

Statistical analysis All analyses were performed using STATA statistical software package [27]. The differences in the clinical characteristics and risk factors between men and women and between subjects with and without vertebral fractures were compared using $t$ tests for continuous variables and chi-square tests for categorical variables. The association between vertebral fracture and risk factors was modeled using logistic regression. Given the known gender differences in prevalence of and risk factors for vertebral fractures, all analyses were a priori stratified by gender. For 173 subjects who did not provide information on young adult height, height loss was imputed via multiple imputation [28] using linear regression estimates based on measured current height, age, race, and gender. Standard errors for model estimates accounted for multiple imputation of height loss [28]. While an increase in precision was observed using the imputed data (more narrow confidence intervals), no substantial differences in the estimates associated with modeled covariates were observed (i.e., the odds ratios, OR, for each predictor were not different with or without imputed values). Prediction models for fracture risk were constructed utilizing data on a random sample consisting of two thirds of the original study cohort. Goodness-of-fit tests for predictive models were carried out using the Hosmer-Lemeshow goodnessof-fit statistic for binary regression [29]. Out-of-sample performance of the resulting predictive models was assessed using the remaining one third of the originally study cohort as a validation sample.

\section{Results}

Among the 974 subjects who consented to participate in the study, 51 were excluded from analysis because they had uninterpretable VFAs, and 31 because they had a single grade 1 fracture, leaving 892 (795 women) subjects for analysis. (Including patients with grade 1 fractures in the fracture group resulted in qualitatively similar conclusions but lower strength of association between vertebral fractures and risk factors.) The clinical characteristics of the participants are shown in Table 1. Women with and without fractures were significantly different in all of the risk factors of interest (Table 1). A higher percentage of women with fractures were receiving pharmacologic therapy for osteoporosis, although this difference was not significant when controlling for presence of osteoporosis by BMD criteria.

Results for women

Association of vertebral fractures with risk factors

Age was a significant predictor of vertebral fractures alone and when controlled for BMD T-score (Table 2). The prevalence of vertebral fractures did not increase until age 60 (Fig. 1a) but then approximately doubled with each decade, with a progressive increase in probability of fracture with increasing age (Table 3). Based on this observation, the variable we used was "age over 50". BMD T-score was a significant predictor of fractures with approximate doubling of the probability of having vertebral fractures for each 1 unit decrease in the T-score, particularly below -2 (Fig. 1b, Tables 2 and 3). The association of vertebral fractures with BMD was diminished but not eliminated when age was added to the model (Table 2). Compared to those with normal BMD, the risk of having vertebral fractures was significantly higher in women with osteoporosis but not in those with osteopenia (Table 3), with the probability of fracture approximately doubling for 1 unit decrease in $\mathrm{T}$ score below -2 (Fig. $1 \mathrm{~b}$ and Table 3). Height loss was also associated with vertebral fractures (Table 2) even when controlling for age and BMD, with prevalence of vertebral fractures doubling for each inch of height loss above $1 \mathrm{in}$. (Fig. 1c and Table 3). Use of glucocorticoids was a significant predictor of vertebral fractures with the strength of association increasing when age was added in the model (Table 2).

Combinations of risk factors When combined in a multivariate regression analysis, all of the risk factors were still significantly associated with prevalent vertebral fractures (Table 2). Based on the area under the receiver operating characteristic curve (ROC curve; 0.850 ), the combination of risk factors predicted the presence of vertebral fractures better than any individual factor. There were no significant interactions between the predictors and no significant effect of, or interactions with, body weight, race, calcium intake, self-reported physical activity, and use of estrogen, tobacco, or alcohol (data not shown).

The additive effect of multiple risk factors was captured by "risk factor index" (RFI) calculated using the regression 
Table 1 Clinical characteristics of women and men with and without vertebral fractures

\begin{tabular}{|c|c|c|c|c|c|c|}
\hline \multirow[b]{3}{*}{ Characteristic } & \multicolumn{3}{|l|}{ Women $(n=795)$} & \multicolumn{3}{|l|}{ Men $(n=97)$} \\
\hline & \multicolumn{3}{|l|}{ Vertebral fractures } & \multicolumn{3}{|l|}{ Vertebral fractures } \\
\hline & $\begin{array}{l}\text { No } \\
(n=649)\end{array}$ & $\begin{array}{l}\text { Yes } \\
(n=146)\end{array}$ & $p$ value $^{\mathrm{a}}$ & $\begin{array}{l}\text { No } \\
(n=67)\end{array}$ & $\begin{array}{l}\text { Yes } \\
(n=30)\end{array}$ & $p$ value $^{\mathrm{a}}$ \\
\hline Age, years & $61.2(19-92)$ & $70.5(20-95)$ & $<0.0001$ & $58.1(20-90)$ & $63.1(34-87)$ & 0.15 \\
\hline \multicolumn{7}{|l|}{ Race } \\
\hline African & $210(81 \%)$ & $49(19 \%)$ & 0.21 & $16(73 \%)$ & $6(27 \%)$ & 0.42 \\
\hline Caucasian & $398(82 \%)$ & $88(18 \%)$ & & $48(69 \%)$ & $22(31 \%)$ & \\
\hline Hispanic & $12(67 \%)$ & $6(33 \%)$ & & $1(33 \%)$ & $2(67 \%)$ & \\
\hline Asian & $29(91 \%)$ & $3(9 \%)$ & & $2(100 \%)$ & $0(0 \%)$ & \\
\hline BMD T-score ${ }^{\mathrm{b}}$ & $-2.2(-6$ to 2.1$)$ & $-3.0(-5.2$ to 0$)$ & $<0.0001$ & $-2.1(-3.9$ to 0.9$)$ & $-3.0(-5.2$ to -0.5$)$ & 0.0001 \\
\hline Lumbar spine & $-1.5(-5.3$ to 3.2$)$ & $-2.1(-5.2$ to 2.4$)$ & $<0.0001$ & $-1.2(-3.9$ to 2.6$)$ & $-2.5(-5.2$ to 2.1$)$ & 0.0002 \\
\hline Femoral neck & $-2.0(-6.0$ to 2.3$)$ & $-2.7(-4.9$ to 0.3$)$ & $<0.0001$ & $-1.8(-3.5$ to 2.2$)$ & $-2.5(-4.2$ to -0.3$)$ & 0.002 \\
\hline Total hip & $-1.4(-5.3$ to 3.1$)$ & $-2.2(4.6$ to 0.7$)$ & $<0.0001$ & $-2.3(-4.3$ to -0.3$)$ & $-2.3(-4.3$ to -0.3$)$ & 0.001 \\
\hline Heel & $-0.8(-4$ to 4.5$)$ & $-1.5(-4.1$ to 1.7$)$ & $<0.0001$ & $-1.1(-4.2$ to 2.8$)$ & $-1.9(-4.8$ to 2.1$)$ & 0.018 \\
\hline Height loss, inches & $0.9(0-7)$ & $2.0(0-7)$ & $<0.0001$ & $1.3(0-6)$ & $1.9(0-7)$ & 0.04 \\
\hline Non-vertebral fractures & $143(22 \%)$ & $63(45 \%)$ & $<0.001$ & $14(22 \%)$ & $4(13 \%)$ & 0.34 \\
\hline Self-reported vertebral fractures & $5(0.8 \%)$ & $35(24 \%)$ & $<0.001$ & $0(0.0 \%)$ & $7(23 \%)$ & $<0.001$ \\
\hline Glucocorticoid use & $99(15 \%)$ & $40(27 \%)$ & $<0.001$ & $27(40 \%)$ & $10(33 \%)$ & 0.51 \\
\hline Height, inches & $63.3(51-73)$ & $61.6(53-69)$ & $<0.001$ & $68.5(62-74)$ & $67.4(61-74)$ & 0.15 \\
\hline Weight, pounds & $152(74-300)$ & $145(80-255)$ & 0.025 & $181(119-284)$ & $171(112-283)$ & 0.22 \\
\hline Osteoporosis therapy & $235(36 \%)$ & $70(48 \%)$ & 0.008 & $21(31 \%)$ & $10(33 \%)$ & 0.85 \\
\hline
\end{tabular}

Results are given as mean (range) for continuous variables and number (\%) for categorical variables

${ }^{a} p$ values were derived from $t$ test for continuous variables and chi-square test for categorical variables

${ }^{\mathrm{b}}$ Lowest of lumbar spine, femoral neck, or total hip T-score

coefficients derived from the multivariate regression analysis from Table 2:

$\mathrm{RFI}=0.75 \times$ age $($ decade over 50$)-0.26 \times \mathrm{T}$

- score (lowest of hip and spine) $+0.24 \times$ inch of height loss

+0.99 (if history of glucocorticoids use) +0.85 (if history of non-vertebral fracture $)+4$ (if self-reported history of vertebral fracture)

The RFI predicted the presence of fractures well as evidenced by the Hosmer-Lemeshow goodness-of-fit test $\left(\chi^{2}=1.09, p\right.$ value $\left.=0.78\right)$. We also considered the performance of the index developed on the random sample of two thirds of the study population on the remaining one third of subjects in our validation dataset. The area under the ROC for predicting the presence of vertebral fracture via the RFI was 0.745 in the remaining one third of subjects in whom the model was tested. RFI performed better in subjects who were receiving therapy for osteoporosis than in untreated patients as evidenced by a higher area under the ROC curve of 0.900 [95\% confidence interval (CI) of $0.860,0.940]$ vs. $0.790(0.733,0.846)$.
The prevalence of vertebral fractures according to different levels of RFI is shown in Fig. 1d. In our study sample which had $18.4 \%$ prevalence of vertebral fractures, choosing an index $\geq 2$ as a cut-off point resulted in the optimal ratio of sensitivity to specificity (Table 4). With index level of $\geq 3$ as a cut-off, the specificity was higher but the sensitivity was unacceptably low. Table 4 shows the performance of different levels of index at different prevalence of vertebral fractures. For example, vertebral fractures prevalence of $15 \%$, having an index $\geq 2$, has a positive predictive value of $24 \%$, while the index $<2$ has negative predictive value of $97 \%$. In other words, while the (pre-test) odds of having vertebral fracture(s) is 0.18 for all subjects, a subject with an index $\geq 2$ has the (post-test) odds of having vertebral fracture of 0.32 [post-test odds $(+)$ in Table 4]. In contrast, a subject with an index $<2$ has odds of having fracture(s) of only 0.028 [post-test odds $(-)$ in Table 4]. If all subjects were to have VFA scan, the number needed to scan and cost of VFA scanning (assuming \$20/ scan) needed to find one subject with vertebral fracture would be six subjects and $\$ 120$. Scanning only subjects 
Table 2 Association of risk factors and prevalent vertebral fractures in women, expressed as odds ratio of having a fracture, derived from logistic regression with presence of vertebral fractures as a binary outcome and each risk factor alone or when controlled for other risk factors, all risk factors combined, or FRAX

\begin{tabular}{|c|c|c|c|}
\hline & OR $(95 \% \mathrm{CI})$ & $p$ value & ROC $(95 \%$ CI $)$ \\
\hline \multicolumn{4}{|l|}{ Individual risk factors } \\
\hline Age/decade & $1.9(1.6,2.2)$ & $<0.001$ & \multirow{3}{*}{$0.719(0.67,0.76)$} \\
\hline Age/decade over 50 & $2.1(1.8,2.6)$ & $<0.001$ & \\
\hline Age over 50 controlled for BMD & $1.9(1.5,2.3)$ & $<0.001$ & \\
\hline BMD T-score/1 unit decrease & $1.9(1.6,2.3)$ & $<0.001$ & \multirow[t]{2}{*}{$0.679(0.63,0.73)$} \\
\hline Controlled for age over 50 & $1.6(1.3,1.9)$ & $<0.001$ & \\
\hline Height loss $/ 1$ in. & $1.7(1.5,1.9)$ & $<0.001$ & \multirow[t]{4}{*}{$0.689(0.64,0.74)$} \\
\hline Controlled for age over 50 & $1.4(1.2,1.6)$ & $<0.001$ & \\
\hline Controlled for BMD & $1.6(1.4,1.8)$ & $<0.001$ & \\
\hline Controlled for age over 50 and BMD & $1.4(1.2,1.6)$ & $<0.001$ & \\
\hline Glucocorticoid use & $2.1(1.3,2.7)$ & 0.001 & \multirow[t]{4}{*}{$0.561(0.52,0.60)$} \\
\hline Controlled for age over 50 & $3.2(2.0,5.1)$ & $<0.001$ & \\
\hline Controlled for BMD & $2.1(1.3,3.2)$ & 0.001 & \\
\hline Controlled for age over 50 and BMD & $3.0(1.9,4.8)$ & $<0.001$ & \\
\hline Non-vertebral fracture & $2.8(1.9,4.1)$ & $<0.001$ & \multirow[t]{4}{*}{$0.612(0.57,0.66)$} \\
\hline Controlled for age over 50 & $2.5(1.6,3.7)$ & $<0.001$ & \\
\hline Controlled for BMD & $2.2(1.5,3.3)$ & $<0.001$ & \\
\hline Controlled for age over 50 and $\mathrm{BMD}$ & $2.2(1.4,3.3)$ & $<0.001$ & \\
\hline Self-reported vertebral fracture & $41(16,106)$ & $<0.001$ & \multirow[t]{4}{*}{$0.616(0.58,0.65)$} \\
\hline Controlled for age over 50 & $65(23,183)$ & $<0.001$ & \\
\hline Controlled for BMD & $37(14,99)$ & $<0.001$ & \\
\hline Controlled for age over 50 and $\mathrm{BMD}$ & $59(21,168)$ & $<0.001$ & \\
\hline \multicolumn{4}{|l|}{ Combined risk factors } \\
\hline $\begin{array}{l}\text { Age/decade over } 50 \\
\text { T-score/1 unit decrease }\end{array}$ & $\begin{array}{l}2.1(1.7,2.7) \\
1.3(1.0,1.6)\end{array}$ & $\begin{array}{r}<0.001 \\
0.027\end{array}$ & \multirow{5}{*}{$0.850(0.81,0.89)$} \\
\hline Height loss/1 in. & $1.3(1.1,1.5)$ & 0.005 & \\
\hline Glucocorticoid use & $2.7(1.5,4.7)$ & $<0.001$ & \\
\hline Non-vertebral fracture & $2.4(1.5,3.7)$ & $<0.001$ & \\
\hline Self-reported vertebral fracture & $55(19,164)$ & $<0.001$ & \\
\hline \multicolumn{4}{|l|}{ FRAX } \\
\hline $10 \%$ increase in 10 -year probability of major osteoporotic fracture & $2.4(1.9,2.9)$ & $<0.001$ & $0.722(0.67,0.77)$ \\
\hline
\end{tabular}

OR odds ratio, $95 \%$ CI 95\% confidence interval, $R O C$ area under the receiver operating characteristic curve, $B M D$ bone mineral density

with $\mathrm{RFI} \geq 2$ would decrease these figures by $50 \%$ (three subjects and \$60).

Association of vertebral fractures with $F R A X^{\circledR}$ In 744 women who were over 40 (which permitted FRAX calculation), there was a significant $(p<0.001)$ association between 10-year probability of major osteoporotic fractures (FRAX_MO) and prevalent vertebral fractures (Table 2), although the area under the ROC curve was significantly $(p<0.0001)$ lower than that resulting from RFI model (Table 2). Using different levels of FRAX MO as a cut-off point for detection of prevalent vertebral fractures, the sensitivity and specificity were $75 \%(95 \%$ CI 68,82$)$ and $63 \%(60,67)$ for FRAX MO of $10 \%$, and $59 \%(51,67)$ and $80 \%(77,82)$ for FRAX_MO of $15 \%$. Lower levels of FRAX_MO had higher sensitivity but lower specificity: for FRAX_MO of $7 \%$, the sensitivity and specificity were $85 \%$ $(79,91)$ and $44 \%(40,48)$ and for FRAX_MO of 5\% they were $92 \%(87,96)$ and $28 \%(24,31)$. Although FRAX is meant to be applied to untreated patients, we found that the prediction of vertebral fractures by FRAX was if anything higher in the treated patients [ROC of $0.776(0.711,0.842)$ ] than in untreated patients $[0.721(0.655,0.786)]$.

Results for men

The prevalence of vertebral fractures was significantly higher in men than in women $(31 \%$ vs. $18 \%, p=0.003)$. Men with 

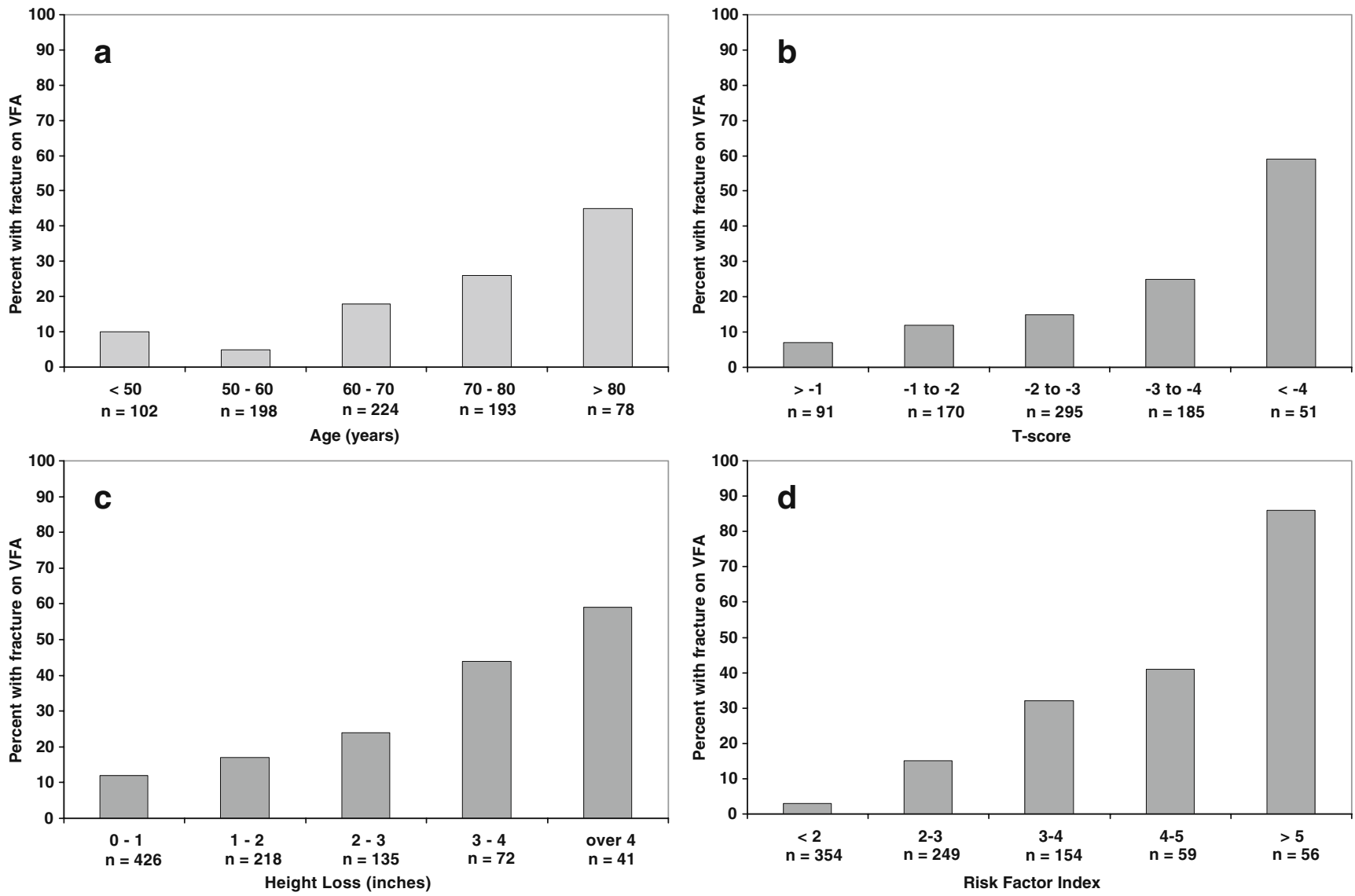

Fig. 1 Prevalence of vertebral fractures relative to a age, $\mathbf{b}$ BMD T-score, $\mathbf{c}$ height loss, and $\mathbf{d}$ level of RFI. $n$ number of women in each strata

vertebral fractures were younger than women $(63.1 \pm 2.3$ vs. $70.5 \pm 1.1, p=0.006)$, and had lower prevalence of nonvertebral fractures $(13 \%$ vs. $45 \%, p=0.001)$, but did not differ in other predictors. Among men, only BMD was predictive of vertebral fracture in a logistic regression analysis, with an OR of $2.7(95 \% \mathrm{CI}=1.6,2.8)$ per each unit decrease in the T-score and area under the ROC curve of 0.738 . While height loss was also associated with vertebral fractures (OR of 1.4 per 1 in. of height loss, $p=0.05$ ), this association was not significant when controlled for BMD.

\section{Discussion}

Using data from 795 women referred for BMD measurement at a university hospital, we developed a simple decision-making tool which incorporates clinical risk factors and BMD results to identify patients who should undergo VFA during their densitometry visit. Currently, the approach to bone densitometry is changing so that, at least in some regions of the world, treatment decisions will rely not on BMD alone but on absolute fracture risk calculated from BMD and clinical risk factors using a FRAX ${ }^{\circledR}$ (Fracture Risk Assessment) tool [20], introduced in 2008 by the World Health Organization (WHO) and endorsed by the National Osteoporosis Foundation [30]. Among the risk factors used for our VFA decision tool, age, BMD T-score, history of fracture, and glucocorticoid use will already be obtained for FRAX calculation. Thus, the patients will need to answer only two additional questions: young adult height (to calculate height loss) and history of vertebral (spine) fractures.

The risk factors included in our model are similar to those suggested by Vogt [15] and Kaptoge [16] for selecting subjects from a general population for spine radiography for the purpose of detecting vertebral fractures. Our model differs from the other two in that it incorporates BMD results, which are readily available during densitometry visit, and glucocorticoid use, which is a common indication for densitometry and is strongly associated with vertebral fractures both in our study (Table 2) and in studies of glucocorticoid-treated patients [17, 19]. Inclusion of glucocorticoid use in our model is supported by our observation that even when controlling for other risk factors, use of glucocorticoids still confers a two to three times higher risk of having vertebral fractures (Table 2).

We also compared the results of our model to the ISCD 2007 official position on indications for VFA [14, 31]. In our 
Table 3 Odds ratio of having vertebral fracture(s) with increasing age, decreasing BMD T-score, increasing height loss, or increasing value of risk factor index

\begin{tabular}{|c|c|c|}
\hline Risk factor & OR $(95 \% \mathrm{CI})$ & $p$ value \\
\hline \multicolumn{3}{|c|}{ Age (compared to less than 60 years) } \\
\hline $60-70$ years & $2.1(0.9,4.3)$ & 0.054 \\
\hline $70-80$ years & $3.2(1.6,6.7)$ & 0.002 \\
\hline Over 80 years & $7.5(3.4,16.5)$ & $<0.001$ \\
\hline \multicolumn{3}{|c|}{ T-score WHO classification (vs. normal) } \\
\hline Osteopenia & $2.3(0.9,5.5)$ & 0.068 \\
\hline Osteoporosis & $4.9(2.1,11.5)$ & $<0.001$ \\
\hline \multicolumn{3}{|c|}{ T-score (compared to over -1 ) } \\
\hline Between -1 and -2 & $1.9(0.7,4.9)$ & 0.190 \\
\hline Between -2 and -3 & $2.5(1.0,6.0)$ & 0.045 \\
\hline Between -3 and -4 & $4.7(1.9,11.4)$ & 0.001 \\
\hline Below -4 & $20.2(7.5,54.9)$ & $<0.001$ \\
\hline \multicolumn{3}{|c|}{ Height loss (compared to $<1$ in.) } \\
\hline $1-2$ in. & $1.7(1.0,2.8)$ & 0.043 \\
\hline $2-3$ in. & $2.6(1.5,4.4)$ & 0.001 \\
\hline $3-4$ in. & $7.5(4.1,13.9)$ & $<0.001$ \\
\hline Over 4 in. & $10.8(5.2,22.5)$ & $<0.001$ \\
\hline \multicolumn{3}{|c|}{ Risk factor index ${ }^{\mathrm{a}}$ (compared to $<1$ ) } \\
\hline $1-2$ & $5.7(0.7,45.1)$ & 0.099 \\
\hline $2-3$ & $14.9(2.0,111.8)$ & 0.009 \\
\hline $3-4$ & $35.8(4.8,266.4)$ & $<0.001$ \\
\hline$>4$ & $190.0(25.6,1408)$ & $<0.001$ \\
\hline
\end{tabular}

OR odds ratio, $95 \%$ CI 95\% confidence interval

${ }^{a}$ Risk factor index is derived using coefficients from a logistic regression model which had vertebral fractures as outcome and all risk factors from Table 1 as predictors study population, the RFI $\geq 2$, which we propose as a cut-off for prompting VFA, provides similar sensitivity and specificity as the ISCD official position (data not shown). The advantage of our model, however, is that it incorporates multiple risk factors in the same model and includes them as continuous variables instead of selecting pre-defined cut-off points to be used as an indication. This allows the model to capture the additive effects of several risk factors and to detect the increase in probability of fracture along the continuum of values of the predictors (Fig. 1a-c). For example, the full gradation of increase in fracture risk associated with decreasing BMD T-score was lost by stratifying this continuous variable into the three WHO diagnostic categories of normal BMD, osteopenia, and osteoporosis (Table 3). Using FRAX ${ }^{\circledR}$ to select patients for VFA also had reasonable sensitivity and specificity albeit not as good as our RFI. The advantage of our model, in addition to its better performance, is that it requires fewer questions than needed for the FRAX calculation. It should be noted, however, that FRAX is not a tool for predicting vertebral fractures, which may explain its inferior performance. The reason we included it in our analysis is because it is likely that calculation of FRAX will become a standard procedure in densitometry, and we wanted to determine whether it could also be used to decide who should have VFA testing. In a recent report from a densitometry practice in the UK, Middleton et al. also concluded that the selection of patients for VFA should be based on a calculated index rather than individual risk factors or BMD measurement [32].

Contrary to population studies which report lower prevalence of vertebral fractures in men compared to

Table 4 Diagnostic utility of the Risk Factor Index (RFI) at two different cut-off points: sensitivity, specificity, and likelihood ratios (95\% confidence intervals); and positive and negative predictive values and corresponding post-test odds at different levels of vertebral fracture prevalence

\begin{tabular}{|c|c|c|c|c|c|c|}
\hline & \multicolumn{3}{|l|}{$\mathrm{RFI} \geq 2$} & \multicolumn{3}{|l|}{$\mathrm{RFI} \geq 3$} \\
\hline Sensitivity & \multicolumn{3}{|l|}{$93 \%(87,96)$} & \multicolumn{3}{|c|}{$77 \%(69,83)$} \\
\hline Specificity & \multicolumn{3}{|l|}{$48 \%(45,52)$} & \multicolumn{3}{|l|}{$76 \%(72,79)$} \\
\hline Likelihood ratio $(+)$ & \multicolumn{3}{|c|}{$1.79(1.6,2.0)$} & \multicolumn{3}{|c|}{$3.13(2.7,3.7)$} \\
\hline \multirow[t]{2}{*}{ Likelihood ratio (-) } & \multicolumn{3}{|c|}{$0.16(0.09,0.28)$} & \multicolumn{3}{|c|}{$0.31(0.23,0.42)$} \\
\hline & \multicolumn{3}{|l|}{$\mathrm{RFI} \geq 2$} & \multicolumn{3}{|l|}{$\mathrm{RFI} \geq 3$} \\
\hline Prevalence of VFx & $10 \%$ & $15 \%$ & $20 \%$ & $10 \%$ & $15 \%$ & $20 \%$ \\
\hline PPV (\%) & 16.6 & 24.0 & 30.9 & 25.8 & 35.6 & 43.9 \\
\hline$(95 \% \mathrm{CI})$ & $(15.4,17.8)$ & $(22.5,25.7)$ & $(29.1,32.8)$ & $(22.8,29.0)$ & $(32.0,39.4)$ & $(40.0,47.9)$ \\
\hline NPV (\%) & 98.3 & 97.3 & 96.3 & 96.7 & 94.8 & 92.8 \\
\hline$(95 \% \mathrm{CI})$ & $(97.0,99.0)$ & $(95.3,98.5)$ & $(93.5,97.9)$ & $(95.6,97.5)$ & $(93.2,96.1)$ & $(90.6,94.6)$ \\
\hline Pre-test odds (given) & 0.111 & 0.176 & 0.25 & 0.111 & 0.176 & 0.25 \\
\hline Post-test odds (+) & 0.199 & 0.316 & 0.448 & 0.348 & 0.553 & 0.783 \\
\hline$(95 \% \mathrm{CI})$ & $(0.18,0.22)$ & $(0.29,0.35)$ & $(0.41,0.49)$ & $(0.30,0.41)$ & $(0.47,0.65)$ & $(0.67,0.92)$ \\
\hline Post-test odds (-) & 0.017 & 0.028 & 0.039 & 0.034 & 0.054 & 0.077 \\
\hline$(95 \% \mathrm{CI})$ & $(0.03,0.01)$ & $(0.05,0.02)$ & $(0.07,0.02)$ & $(0.05,0.02)$ & $(0.07,0.04)$ & $(0.10,0.06)$ \\
\hline
\end{tabular}


women $[16,33]$, we found that males had higher probability of having vertebral fractures relative to females (Table 1). This is likely due to a referral bias, with men undergoing bone densitometry if they have significant pathology associated with osteoporosis, such as history of glucocorticoid use or organ transplantation, while women are referred for screening purposes. The prevalence of vertebral fracture in our male subjects $(34 \%)$ was very similar to that reported in a study which examined VFA results in men referred for BMD testing, where the prevalence of vertebral fractures was $32 \%$ [34]. It is not likely that the higher prevalence of vertebral fractures in men was due to traumatic vertebral fractures because we found a strong association between vertebral fractures and low BMD T-scores, which would not be expected had the vertebral fractures been of traumatic origin.

The model we derived is likely to perform well in assessing the probability of finding vertebral fractures on VFA in women referred for densitometry. This is supported by our observation that the model we derived from two thirds of subjects (randomized on main risk factors, see Results) performed well in the remaining one third of subjects. In addition, the values of regression coefficients (odds ratio) from our model are similar to values reported by Vogt [15] and Kaptoge [16], and the performance of our model and that of Vogt and Kaptoge models in our study population are very similar (data not shown). Nevertheless, a further study in a different population may help to fully test the predictive value of our model for its inclusion into routine densitometry operation.

One could argue that VFA is not useful unless it impacts the treatment decisions, which is most likely to occur in subjects with BMD diagnosis of osteopenia. In practice, however, many clinicians find information on vertebral fractures useful even in patients who have osteoporosis by BMD criteria. For example, in a treatment-naïve patient with vertebral fractures, at least some experts would first use an anabolic rather than an antiresorptive drug; a drug holiday may not be offered after 5 years of bisphosphonate use to a patient with vertebral fractures; or a patient who is reluctant to use pharmacotherapy may be more likely to comply with the treatment if vertebral fractures are discovered.

There are some limitations to our study. The number of men in our study is too small to permit calculation of risk factor score for men. However, inclusion of data from men in our study is nevertheless important in that it illustrates that men referred for densitometry have a higher probability of having vertebral fractures than women. A second possible limitation may be that we examined a convenience sample rather than all 10,547 patients referred for densitometry in our institution. Although there was no systematic bias, it is possible that the study population was more "osteoporotic" because many of our study subjects were clinic patients of the author (TJV), who has an osteoporosis referral practice. While this may lower the generalizability of our findings in terms of point estimation, the underlying qualitative conclusions would be unlikely to change in a lower risk population. The third possible limitation is that we used a larger questionnaire, and thus a short version that we propose for generating RFI was not directly tested. However, the shorter questionnaire is, if anything, easier to complete and more likely to be accurate. Finally, the best use of a tool like this would be to incorporate it into the densitometry software, which would require approval by regulatory agencies. Although this may present an obstacle, it is likely that if this general approach is accepted by the medical community, the efforts to secure the approval may be less difficult compared to approval of new devices or new approaches such as FRAX. This is because VFA has already been approved, is not associated with significant risk to the patient, and because having a tool to help select the patients for VFA testing is likely to ultimately improve the cost-effectiveness of the procedure.

Our study also has significant strengths. It examined the risk factors in patients undergoing densitometry rather than in the general population and thus is better applicable to densitometry in general. In addition, we examined fractures detected by VFA and thus can provide information that is pertinent to future use of this methodology in contrast to earlier studies which used radiographs. Finally, our study population is multiracial, which makes our conclusions generalizable to broader populations than previously studied.

In summary, we developed a decision-making tool, which includes clinical risk factors and BMD measurement to select patients for VFA imaging. The proposed model could be incorporated into densitometry software to prompt the technologist to perform VFA at the level of the risk factor index which will be determined for each densitometry center based on the expected prevalence of vertebral fractures.

\section{Conflict of interest None.}

Open Access This article is distributed under the terms of the Creative Commons Attribution Noncommercial License which permits any noncommercial use, distribution, and reproduction in any medium, provided the original author(s) and source are credited.

\section{References}

1. Ettinger B, Black DM, Nevitt MC, Rundle AC, Cauley JA, Cummings SR, Genant HK (1992) Contribution of vertebral deformities to chronic back pain and disability. The Study of Osteoporotic Fractures Research Group. J Bone Miner Res 7:449-456

2. Burger H, Van Daele PL, Grashuis K, Hofman A, Grobbee DE, Schutte HE, Birkenhager JC, Pols HA (1997) Vertebral deformi- 
ties and functional impairment in men and women. J Bone Miner Res $12: 152-157$

3. Cockerill W, Lunt M, Silman AJ, Cooper C, Lips P, Bhalla AK, Cannata JB, Eastell R, Felsenberg D, Gennari C, Johnell O, Kanis JA, Kiss C, Masaryk P, Naves M, Poor G, Raspe H, Reid DM, Reeve J, Stepan J, Todd C, Woolf AD, O'Neill TW (2004) Healthrelated quality of life and radiographic vertebral fracture. Osteoporos Int 15:113-119

4. Melton LJ 3rd, Atkinson EJ, Cooper C, O'Fallon WM, Riggs BL (1999) Vertebral fractures predict subsequent fractures. Osteoporos Int 10:214-221

5. Lindsay R, Silverman SL, Cooper C, Hanley DA, Barton I, Broy SB, Licata A, Benhamou L, Geusens P, Flowers K, Stracke H, Seeman E (2001) Risk of new vertebral fracture in the year following a fracture. JAMA 285:320-323

6. Center JR, Bliuc D, Nguyen TV, Eisman JA (2007) Risk of subsequent fracture after low-trauma fracture in men and women. JAMA 297:387-394

7. Cauley JA, Hochberg MC, Lui LY, Palermo L, Ensrud KE, Hillier TA, Nevitt MC, Cummings SR (2007) Long-term risk of incident vertebral fractures. JAMA 298:2761-2767

8. Ross PD, Davis JW, Epstein RS, Wasnich RD (1991) Pre-existing fractures and bone mass predict vertebral fracture incidence in women. Ann Intern Med 114:919-923

9. Siris ES, Genant HK, Laster AJ, Chen P, Misurski DA, Krege JH (2007) Enhanced prediction of fracture risk combining vertebral fracture status and BMD. Osteoporos Int 18:761-770

10. Cooper C, O'Neill T, Silman A (1993) The epidemiology of vertebral fractures. European Vertebral Osteoporosis Study Group. Bone 14:S89-S97

11. Fink HA, Milavetz DL, Palermo L, Nevitt MC, Cauley JA, Genant HK, Black DM, Ensrud KE (2005) What proportion of incident radiographic vertebral deformities is clinically diagnosed and vice versa? J Bone Miner Res 20:1216-1222

12. Gehlbach SH, Bigelow C, Heimisdottir M, May S, Walker M, Kirkwood JR (2000) Recognition of vertebral fracture in a clinical setting. Osteoporos Int 11:577-582

13. Delmas PD, van de Langerijt L, Watts NB, Eastell R, Genant H, Grauer A, Cahall DL (2005) Underdiagnosis of vertebral fractures is a worldwide problem: the IMPACT Study. J Bone Miner Res 20:557-563

14. Schousboe JT, Vokes T, Broy SB, Ferrar L, McKiernan F, Roux C, Binkley N (2008) Vertebral fracture assessment: the 2007 ISCD Official Positions. J Clin Densitom 11:92-108

15. Vogt TM, Ross PD, Palermo L, Musliner T, Genant HK, Black D, Thompson DE (2000) Vertebral fracture prevalence among women screened for the Fracture Intervention Trial and a simple clinical tool to screen for undiagnosed vertebral fractures. Fracture Intervention Trial Research Group. Mayo Clin Proc 75:888-896

16. Kaptoge S, Armbrecht G, Felsenberg D, Lunt M, O’Neill TW, Silman AJ, Reeve J (2004) When should the doctor order a spine $\mathrm{X}$-ray? Identifying vertebral fractures for osteoporosis care: results from the European Prospective Osteoporosis Study (EPOS). J Bone Miner Res 19:1982-1993

17. Naganathan V, Jones G, Nash P, Nicholson G, Eisman J, Sambrook PN (2000) Vertebral fracture risk with long-term corticosteroid therapy: prevalence and relation to age, bone density, and corticosteroid use. Arch Intern Med 160:2917-2922

18. van Staa TP, Leufkens HG, Cooper C (2002) The epidemiology of corticosteroid-induced osteoporosis: a meta-analysis. Osteoporos Int 13:777-787

19. Angeli A, Guglielmi G, Dovio A, Capelli G, de Feo D, Giannini S, Giorgino R, Moro L, Giustina A (2006) High prevalence of asymptomatic vertebral fractures in post-menopausal women receiving chronic glucocorticoid therapy: a cross-sectional outpatient study. Bone 39:253-259

20. Kanis J (2008) FRAX WHO Fracture Risk Assessment Tool. http://www.shef.ac.uk/FRAX/

21. Genant HK, Wu CY, van Kuijk C, Nevitt MC (1993) Vertebral fracture assessment using a semiquantitative technique. J Bone Miner Res 8:1137-1148

22. Vokes T, Bachman D, Baim S, Binkley N, Broy S, Ferrar L, Lewiecki EM, Richmond B, Schousboe J (2006) Vertebral fracture assessment: the 2005 ISCD Official Positions. J Clin Densitom 9:37-46

23. Delmas PD, Genant HK, Crans GG, Stock JL, Wong M, Siris E, Adachi JD (2003) Severity of prevalent vertebral fractures and the risk of subsequent vertebral and nonvertebral fractures: results from the MORE trial. Bone 33:522-532

24. Binkley N, Krueger D, Gangnon R, Genant HK, Drezner MK (2005) Lateral vertebral assessment: a valuable technique to detect clinically significant vertebral fractures. Osteoporos Int 16:15131518

25. (2001) Recommendations for the prevention and treatment of glucocorticoid-induced osteoporosis: 2001 update. American College of Rheumatology Ad Hoc Committee on GlucocorticoidInduced Osteoporosis. Arthritis Rheum 44:1496-1503.

26. Hans D, Downs RW Jr, Duboeuf F, Greenspan S, Jankowski LG, Kiebzak GM, Petak SM (2006) Skeletal sites for osteoporosis diagnosis: the 2005 ISCD Official Positions. J Clin Densitom 9:15-21

27. STATA (2003) Stata Statistical Software, Release 10.0. STATA, College Station

28. Little R, Rubin, D (2002) Statistical analysis with missing data. Wiley, New York.

29. Agresti A (1996) Categorical data analysis. Wiley-Interscience, New York.

30. (2008) National Osteoporosis Foundation: Clinician's Guide to Prevention and treatment of Osteoporosis. http://www.nof.org/ professionals/NOF Clinicians\%20 Guide.pdf.

31. 2007 ISCD Official Positions. http://www.iscd.org/Visitors/ positions/OfficialPositions

32. Middleton ET, Gardiner ED, Steel SA (2009) Which women should be selected for vertebral fracture assessment? Comparing different methods of targeting VFA. Calcif Tissue Int 85:203210

33. O'Neill TW, Felsenberg D, Varlow J, Cooper C, Kanis JA, Silman AJ (1996) The prevalence of vertebral deformity in European men and women: the European Vertebral Osteoporosis Study. J Bone Miner Res 11:1010-1018

34. Vallarta-Ast N, Krueger D, Wrase C, Agrawal S, Binkley N (2007) An evaluation of densitometric vertebral fracture assessment in men. Osteoporos Int 18:1405-1410 